\title{
NADP Stimulates DNA Reparation after Thermodynamic Stress in Cardiomyocytes of Aging MDX Mice
}

\author{
E Mikhailova ${ }^{1,3 *}$, I Vezhenkova ${ }^{1}$, D Firsanov ${ }^{1}$, E Kaminskaya ${ }^{1}$, V Kazakov ${ }^{1}$, A Gudkova ${ }^{2}$ and V Mikhailov ${ }^{1}$ \\ ${ }^{1}$ Institute of Cytology, Russian Academy of Sciences, Russia
}

${ }^{2}$ Northwestern Federal Medical Research Center, V.A. Almazov of the Ministry of Health of the Russian Federation, Russia

${ }^{3}$ St. Petersburg State Pediatric Medical University, Ministry of Health of the Russian Federation, Russia

*Corresponding author: E Mikhailova, Ministry of Health of the Russian Federation, 194156, Saint-Petersburg, Thikhoretsky av, Russia

Submission: 眥 November 01, 2018; Published: 眥 November 16, 2018

\begin{abstract}
Using thermodynamic stress we aim to analyze the possibility of regulating the DNA double strand (DSBs) formation in heart tissue of aging mdx mice by intraperitoneal injections of NADP+ which is shown to mediate key regulators of oxygen stress and cell death.
\end{abstract}

Keywords: Heart; Cardiomyocytes; Dynamic Stress; DNA Reparation; MDX Mice

\section{Introduction}

Nowadays there is a significant increase in the survival value of patients due to the drug therapy which, in turn, causes a significant increase of the incidence rate of heart failure and cardiomyopathy developing due to cardiomyocytes death [1]. Thus, one of the main issues of cardiomyocyte biology is their survival under rough circumstances arising provided that there is pathology of the myocardium.

One of the models with genetically determined myocardial dystrophy are mdx mice, where the absence of dystrophin synthesis is accompanied by the development of oxidative stress and of cardiomyopathy signs in the heart of aging mdx mice $[2,3]$.

One of the oxidative stress manifestations in the heart of $\mathrm{mdx}$ mice is the constant presence of DNA fragments $65 \mathrm{kbp}$ in the left ventricles myocardial cells [4]. Low molecular DNA fragments were observed after the so-called thermodynamic stress (TDS) [5]. Formation of low molecular weight DNA fragments coincides with appearance of DNA double-strand breaks (DSBs). DNA endonuclease activity, mitochondrial damage and amyloid deposits in the myocardium of mdx mice [6-8].

One hour after TDS of young mdx mice the fraction of cardiomyocyte nuclei with DNA DSBs reaches $46 \%$ while the proportion of labeled non-muscle cells reaches $9 \%$. In $24 \mathrm{~h}$ the proportion of nuclei with DSB decreases to $9 \%$ and $2 \%$ respectively, indicating the involvement of DNA reparation in the survival of mdx mice cardiomyocytes after TDS. There was also the loss of cardiomyocytes in the myocardium after the TDS [6].
There is increasing evidence that the pool of nicotinamide adenine dinucleotide (NAD+) and its derivatives is depleted under stress conditions and during aging $[9,10]$. We suggested that increased DNA damage and oxygen stress in cardiomyocytes of $\mathrm{mdx}$ mice after TDS also lead to the decrease of NAD+ pool in cells. Here we focused our efforts on the effects of exogenous NADP+ on the DSB in myocardial cells after DS in aging mdx mice.

\section{Materials and Methods}

Identification was performed on 12-month-old male and female mdx mice carrying mutation in DMD gene $(n=12)$ (RRID: IMSR_HAR: 1217). All procedures were approved by the local Ethics Committee of the Institute of Experimental Medicine RAS (St. Petersburg, Russia). All reagents were purchased from SIGMAAldrich (St. Louis, MO, USA) if not indicated otherwise.

Animals were submitted to TDS -- swimming for 5 min in $12{ }^{\circ} \mathrm{C}$ water. There upon animals were given a single intraperitoneal dose of NADP+ solution in water $(700 \mathrm{mg} / \mathrm{kg}$ weight). In $24 \mathrm{~h}$ animals were deeply anesthetized and sacrificed by cervical dislocation. Slides of left cardiac ventricles for histological examination were sectioned into $10-\mu \mathrm{m}$ thickness using cryostat (Bright Instrument Co LTD, GB).

To reveal DNA DSB the phosphorylation product of histone $\mathrm{H} 2 \mathrm{AX}$ was detected by anti- $\gamma \mathrm{H} 2 \mathrm{AX}$ antibodies [11]. Tissue sections were incubated overnight at $4{ }^{\circ} \mathrm{C}$ with polyclonal rabbit antibodies to $\gamma$-H2AX (Abcam, Cambridge, CA, USA, Abcam Cat\# ab11174, RRID: AB_297813) at 1:200 dilution, then incubated for $20 \mathrm{~min}$ in biotinylated goat anti-rabbit IgG (Vector Lab, Burlingame, 
CA), followed by incubation with horseradish peroxidase (HRP)streptavidin for $20 \mathrm{~min}$. The antibody binding sites were visualized through reaction with DAB-H2O2 solution. Results obtained were presented as the means \pm the standard error of measurement (SEM) of at least three animals per group. The total number of cells per each myocardium was about 1000 . When counting the mean values, the number of studied hearts was taken as the number of observations. One-way analysis of variance (ANOVA) followed by post hoc Tukey's multiple comparison test were used to determine statistical significance between groups of young and aging mice. Differences were considered significant at $\mathrm{p}<0.05$.

\section{Results}

In the left ventricle myocardium of aging mdx mice, the fraction of nuclei with a positive staining for $\gamma$-H2AX in the absence of stress is $10.1 \pm 1 \%$ (Table 1 ), which is higher than that of the DSBs accumulation in the myocardium of 3 -month-old animals $(6.7 \pm 0.2 \%$ $(\mathrm{p}<0.05))$. In young $\mathrm{mdx}$ mice TDS leads to the significant increase in the proportion of nuclei with a positive staining for $\gamma-\mathrm{H} 2 \mathrm{AX}$ during first hour (42\%), but then the number returns to the baseline within $24 \mathrm{~h}$, which indicates a sufficiently effective DNA reparation. In aging mdx mice TDS leads to the increase in the proportion of $\gamma$-H2AX-positive nuclei to $15.9 \pm 3 \%$ after $1 \mathrm{~h}$ and $26 \pm 6 \%$ after $24 \mathrm{~h}$. Such dynamics of DSB accumulation doesn't coincide with pattern of DSB in young mdx mice after TDS and C57Bl/6 mice after x-ray irradiation, where $20 \%$ of myocardial cell nuclei retain DSB in $24 \mathrm{~h}$.

Table 1: Proportion of $\gamma$-H2AX-positive nuclei in cardiomyocytes of mdx mice after thermodynamic stress (TDS).

\begin{tabular}{|c|c|c|}
\hline \multirow{2}{*}{ Exposure } & \multicolumn{2}{|c|}{ Time after TDS, $\mathbf{h}$} \\
\cline { 2 - 3 } & $\mathbf{1}$ & $\mathbf{2 4}$ \\
\hline No exposure (control) & \multicolumn{2}{|c|}{$10.1 \pm 1 \%$} \\
\hline DS & $15.9 \pm 3 \%^{*}$ & $26 \pm 6 \% *$ \\
\hline DS, followed by NADP+ administration & $11.2 \pm 2 \%^{*}$ & $10.9 \pm 1 \% *$ \\
\hline
\end{tabular}

${ }^{*} \mathrm{p}<0.05$ against control

After NADP+ administration the fraction of $\gamma$-H2AX-positive nuclei in myocardium of aging mdx mice does not change from the original value and remains at the same level during first $24 \mathrm{~h}$ after DS (see table). Thus, myocardium of aging mdx mice is characterized by higher degree of DSB accumulation in comparison with young animals. We observed marked accumulation of DSB during first $24 \mathrm{~h}$ after DS. The administration of NADP+ prevents this accumulation which may be explained by the intracellular NADP+ and NAD+ pool restoration leading to the decrease of oxygen stress level in cardiomyocytes. The results suggest that exogenous NADP+ may be used as potential antioxidant in DMD treatment for preventing myocardium damage.

\section{References}

1. Leri A, Rota M, Pasqualini FS, Goichberg P, Anversa P (2015) Origin of cardiomyocytes in the adult heart. Circ Res 116(1): 150-166.

2. Tsuitsui H, Kinugava S, Matsushima S (2011) Oxidative stress and heart failure. Am J Physiol Heart Circ Physiol 301(6): 181-190.

3. Zhang GX, Kimura S, Nishiyama A, Shokoji T, Rahman M, et al. (2005) Cardiac oxidative stress in acute and chronic isoproterenol-infused rats. Cardiovasc Res 65(1): 230-238.

4. Kazakov VI, Mikhailov VM (2001) DNA fragmentation of cardiomyocytes of mice mdx and C57B1 after stress. Tsitologiya 43: 72-75.

5. Mikhailov VM, Vezhenkova IV (2007) Double-strand breaks of DNA of C57BL and mdx mouse cardiomyocytes after dynamic stress. Cell and Tissue Biology 1(4): 328-333.

6. Mikhailov VM, Komarov SA, Kazakov VI (2003) Survival and apoptosis of the mouse mdx cardiomyocytes. Tsitologiya 45: 902-903.

7. Percival JM, Siegel MP, Knowels G, Marcinek DJ (2013) Defects in mitochondrial localization and ATP synthesis in the mdx mouse model of Duchenne muscular dystrophy are not alleviated by PDE5 inhibition. Hum Mol Genet 22(1): 153-167.

8. Gusel'nikova VV, Gudkova AY, Semernin EN, Grudinin NA, Krutikov AN, et al. (2017) Characterization of amyloid deposits found in internal organs of mdx mice. Cell and Tissue Biology 11(1): 27-34.

9. Alano CC, Garnier P, Ying W, Higashi Y, Kauppinen TM, et al. (2010) NAD+ depletion is necessary and sufficient for PARP-1-mediated neuronal death. J Neurosci 30(8): 2967-2978.

10. Braidy N, Guillemin GJ, Mansour H, Chan Ling T, Poljak A, et al. (2011) Age related changes in NAD+ metabolism oxidative stress and Sirt1 activity in Wistar rats. PLoS One 6(4): e19194.

11. Gavrilov B, Vezhenkova I, Firsanov D, Solovjeva L, Svetlova M, et al. (2006) Slow elimination of phosphorylated histone $\gamma$-H2AX from DNA of terminally differentiated mouse heart cells in situ. Biochem Biophys Res Commun 347(4): 1048-1052.
Creative Commons Attribution 4.0 International License

For possible submissions Click Here
Submit Article

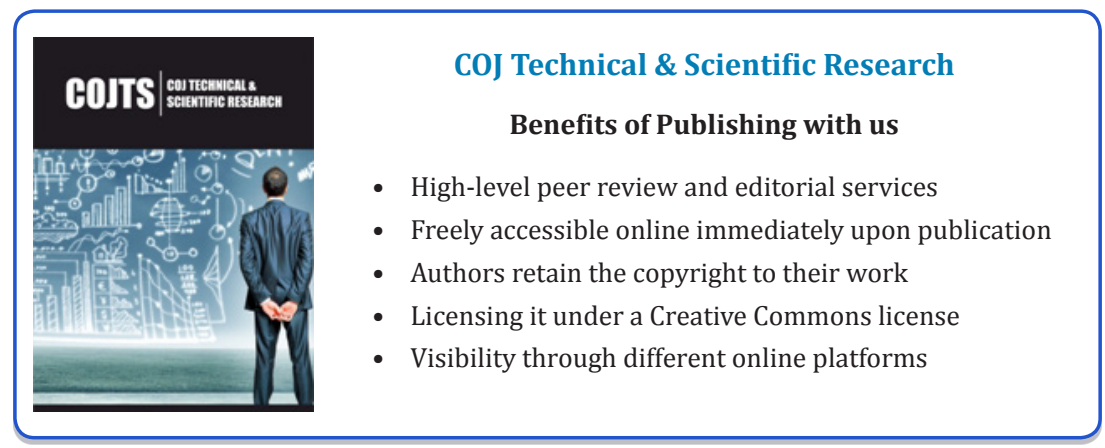

